\title{
Ações do Conselho Tutelar na garantia dos direitos das crianças e adolescentes na Amazônia durante a pandemia do COVID-19
}

\author{
Antônio Vagner Almeida Olavo'; Carmen Pineda Nebot ${ }^{2}$; Francisca Carla Ferreira das Chagas ${ }^{3}$
}

\section{Introdução}

O COVID-19 tem apresentado ao Estado, desafios no âmbito da saúde e de proteção social. Na proteção social, destaca a necessidade de ações que possam garantir que os direitos das crianças e adolescentes não sejam violados, principalmente com a necessidade de isolamento social.

No Brasil como em outros países do mundo, as atividades ligadas a educação tiveram que ser interrompidas, assim como, as atividades comerciais por conta da pandemia do COVID-19, o que tem mudado a rotina das famílias, exigindo dos pais e responsáveis maiores cuidados com as crianças e adolescentes (Marques, Moraes, Hasselmann, Deslandes \& Reichenheim, 2020). Essa mudança de rotina, pode aumentar de forma exponencial os casos de violação dos direitos das crianças e adolescentes, o que exige do Estado, ações voltadas à proteção (Bahia \& Toledo, 2020; Marques, Moraes, Hasselmann, Deslandes \& Reichenheim, 2020).

O fechamento das escolas também pode ter efeitos sociais e de saúde muito prejudicial para as crianças e adolescentes, que na maioria das vezes vivem em situação de pobreza e ampliam as desigualdades existentes. Crianças de famílias de baixa renda vivem em condições que dificultam a escolaridade em casa, devido à ausência de computadores, conexão à internet, precariedade de suas casas e a falta de treinamento de seus pais (Van Lancker \& Parolin, 2020).

Neste contexto, apresenta-se um conjunto de atores que buscam garantir os direitos das crianças e adolescentes que estão previstos no Estatuto da Criança e Adolescente (ECA), por meio da Lei nº 8.069 de 13 de julho de 1990 , dentre eles o Conselho Tutelar. O Conselho Tutelar funciona como uma ponte entre as crianças e adolescente que possuem seus direitos violados com o Estado, principalmente com os órgãos de justiça e social. Para isso, os conselhos tutelares devem mobilizar uma rede de serviços que possam garantir tais direitos (Romagnoli \& Silva 2019).

Para entender, como estão sendo realizadas as ações do Conselho Tutelar durante a pandemia do COVID-19, elegeu-se como campo empírico o município de Benjamin Constant, localizado no estado do Amazonas, no norte do Brasil. A escolha do município se deu por estar localizado na região amazônica, onde existe o contexto urbano e rural (comunidades ribeirinhas indígenas e não indígenas) que por sua vez vivencia o distanciamento dos grandes centros urbanos. Além disso, este município vivencia a realidade fronteirístico com o Peru, onde existe o livre trânsito de pessoas e mercadorias. Outro motivo, foi que o estado do Amazonas tem sido uns dos mais afetados pelo COVID-19, de acordo com o atlas Objetivo do Desenvolvimento Sustentável (2020) no dia 14 de maio de 2020, possuía mais de 15 mil casos registrados com a letalidade em 7,3\%. Sendo que boa parte destes casos estão localizados no interior do Amazonas, onde existe pouca estrutura e recursos hospitalares, o que reforça a necessidade de isolamento social que por sua vez demanda do Estado, ações que promovam a garantia dos direitos das crianças e adolescentes. Sendo também uma área com um PIB per capita muito baixo (R\$ 6.602,92), uma grande população desempregada (94\%), muitas famílias recebendo Bolsa Família (Programa de distribuição de renda do governo brasileiro que ajuda as famílias carentes) e uma população muito jovem (41\% têm entre 0 e 19 anos).

Diante do exposto, acredita-se que o Conselho Tutelar possa ser um órgão de prevenção e de fiscalização para que os direitos das crianças e adolescentes não sejam violados no período de pandemia, como COVID-19. Assim, este ar-

\footnotetext{
Mestrando em Administração na Universidade Federal de Viçosa e Professor da Universidade Federal do Amazonas, Brasil.

E-mail: adm.antoniovagner@hotmail.com

Pesquisadora do GEGOP- CLACSO, Brasil

E-mail: carmenpinedanebot@hotmail.com

Licenciada em Biologia e Química pela Universidade Federal do Amazonas (UFAM) e Pesquisadora do Grupo de Estudos da Gestão Produtiva da

Região da Tríplice Fronteira do Alto Amazonas, Brasil.

E-mail: francarlafe1993@hotmail.com
}

Soc. Infanc. 4, 2020: 185-288 
tigo parte da seguinte questão: quais são as ações para proteger as crianças e adolescentes que estão sendo realizadas pelo Conselho Tutelar do Município de Benjamin Constant -AM durante o período de isolamento social por conta do COVID-19? Para responder tal questão, temos como objetivo: verificar as ações de prevenção e de identificação de casos pelo Conselho Tutelar do município de Benjamin Constant durante o período de isolamento social. Como referencial teórico apresentamos os conceitos e atribuições referente ao conselho tutelar e as principais violações dos direitos das crianças e adolescentes. Como procedimento metodológico foi realizado entrevistas semiestruturada com quatro conselheiros tutelares do município para compreender as ações de prevenção e de demanda causada pelas violações de direitos das crianças e adolescentes.

\section{Procedimento Metodológico}

Para a realização deste estudo, utilizou-se uma abordagem qualitativa, sendo descritiva. A abordagem qualitativa permitiu o emprego de técnica de entrevista semiestruturada com quatro conselheiros tutelares no município de Benjamin Constant - AM. Estes conselheiros foram eleitos por voto popular para o mandato de 2020 a 2024.

Estas entrevistas ocorreram no período de 08 a 12 de maio de 2020, realizada pelo aplicativo WhatsApp. Optou-se por realizar desta forma, por conta do distanciamento entre os pesquisadores e os participantes da pesquisa, além da necessidade de isolamento social.

Após a organização dos áudios foi realizado as transcrições das entrevistas, que posteriormente foi aplicada a análise de conteúdo tendo como critérios a adotados por Bardin (2006) que são pré-análise, exploração do material e tratamento dos resultados. Para garantir o anonimato dos entrevistados estes serão identificados como entrevisto seguido por um número 1 até o 4.

\section{Resultados e Análises}

Em Benjamin Constant de acordo com os dados da Secretaria de Saúde do Estado do Amazonas, no período de 13 de março a 10 de maio de 2020 existem 137 casos registrados do COVID-19 destes 10 óbitos.

No âmbito local, a Prefeitura Municipal de Benjamin Constant tem realizado algumas ações na tentativa de diminuição de contágio como o decreto $n^{\circ} 080$ de 23 de março de 2020, que declara emergência no município de Benjamin Constant - AM, o decreto $\mathrm{n}^{\mathrm{o}} 102$ de 01 de maio de 2020 que prorroga os prazos dos decretos municipais e proíbe a saída de indígenas de suas comunidades, além de adotar o sistema de rodízio de veículos e uso de máscaras na prevenção do COVID-19.

A prefeitura local também instituiu um Comitê Municipal de Prevenção e Enfrentamento ao Contágio pelo COVID-19, por meio do decreto $\mathrm{N}^{\mathrm{o}} 77$ de 19 de março de 2020. Faz parte deste comitê, órgãos ligados a segurança, saúde, justiça, legislativo local, educação e assistência social no município. Uma das ações ligadas às questões sociais, visando a prevenção é a distribuição de produtos de limpezas e alimentos a famílias carentes cadastradas no Programa de Inclusão Social e Cidadania (PISC), principalmente aquelas que possuem idosos, crianças, adolescentes e pessoas no grupo de risco.

Deste modo, inicialmente, o conselho tutelar fez parte do comitê, auxiliando e orientando as famílias quanto a necessidade de isolamento social "Logo no início estivemos junto a equipe de combate ao COVID-19. Juntos fizemos orientações em ruas, becos e nos locais onde a equipe tem ações do comitê. Orientando pais e responsáveis para que evitasse que as crianças e adolescentes não ficassem aglomerados na rua e soltando papagaio, para evitar a transmissão" (Entrevistado 1). Atualmente, por questão de segurança dos conselheiros tutelares o apoio ao comitê, ocorre somente quando solicitado "[...] então quando tem alguma situação de criança ou adolescente em esquinas nas ruas eles nos acionam e vamos com eles até o local e fazemos as devidas orientações, pedindo que fica em casa que os responsáveis tenham um controle sobre os filhos porque na maioria das vezes alegam que o pai permitiu" (Entrevistado 4). O entrevistado 1, reforça que estão atuando em "[...] escala normal de trabalho com plantões de dois conselheiros por turnos". Algumas orientações estão sendo realizadas por meio das tecnologias digitais e redes sociais como o Facebook e WhatsApp “[...] em casos de dúvidas e se detectar caso de extrema urgência, fazemos os procedimentos presenciais cabíveis." (Entrevistado 2).

Quanto às comunidades ribeirinhas e indígenas por questões logísticas, e para tentar diminuir o risco de contágio o município baixou um decreto que proibindo a circulação dos indígenas no município no prazo de 15 dias, o que não tem permitido realizar ações frequentes "[...] por falta de apoio nas logísticas” (Entrevistado 1). Outro conselheiro relatou que nas comunidades houve casos de orientação que foi realizada via Whatsapp, mas também teve outro caso que teve a necessidade de fazer a visita in loco "[...] outros casos tivemos que se deslocar para a comunidade no transporte do comitê. Por isso precisamos nos deslocar pelo transporte fluvial que é uma das nossas dificuldades" (Entrevistado 2).

Os direitos mais violados no município de acordo com os conselheiros são a negligência dos pais e responsáveis, e os maus tratos, agressões físicas e psicológicas. De acordo com o conselheiro a negligência ocorre quando os “[...] pais não estão com as crianças, mas também, ocorre quando deixam eles saírem de casa” (Entrevistado 3). Além 
dos pais muitos das vezes permitirem que seus filhos fiquem na rua sem necessidade, os conselheiros apontam que muitos dos pais levam seus filhos para atividades essenciais sem necessidades, como compras nos supermercados, farmácias e outros. Segundo o entrevistado 4 "[...] nós tivemos negligência, agressão física e logo no início da pandemia abandono de incapaz". Contudo, "até o presente momento durante essa pandemia estão estáveis as violações" (Entrevistado 2). A negligência foi apontada por Pineda, Olavo \& Andrade (2019) como sendo o principal direito violado, podendo ser previsto em períodos de pandemia. O trabalho infantil também foi evidenciado nesse contexto de pandemia "[...] em uma das nossas andanças sobre a questão de orientação, nós encontramos duas crianças em situação de trabalho infantil”" (Entrevistado 3).

As medidas tomadas pelos conselheiros em caso de violação dos direitos são com base na ECA de acordo com o entrevistado 2 "Atendimento às crianças e Adolescentes aplicando as medidas previstas no Art. 101 parágrafos I, II, V (Psicológico); Atendimento e Aconselhamento aos pais ou responsável, aplicando as medidas previstas no Art. 129. Parágrafo. III e VII.; Requisições de serviços públicos.; Encaminhamento ao Ministério Público e delegacia de polícia Civil.; Encaminhamento à autoridade judiciária os casos de sua competência.; Expedição de Notificações. " Além do "artigo 7 e 18" (Entrevistado 4).

Alguns desafios são apresentados pelos conselheiros quanto a realização das suas ações, tais como: a) falta de equipamento de proteção individual (EPI) para os conselheiros realizarem as visitas in loco ou atividade de rondas nas ruas; b) desrespeito dos cidadãos quantos as orientações prestadas quanto ao isolamento social; c) necessidade de um transporte fluvial, para que possa ser realizado visitas nas comunidades ribeirinhas; d) dificuldade quanto ao acesso e a navegabilidade de internet, pois nesta região não existe fibra ótica, sendo o acesso via satélite e/ou telefonia móvel que também possui baixa qualidade; e) fechamento de alguns órgãos de apoio aos direitos das crianças e adolescente no município; f) falta de orientação dos pais e responsáveis para que as crianças e adolescentes fiquem em casa. Alguns destes desafios são apontados por Romagnoli e Silva (2019) em contexto onde ainda não existia a pandemia, sendo um problema estrutural do conselho tutelar.

Ressalta-se que o outro desafio e uma preocupação demonstrada pelos conselheiros é a contaminação a entrevistada 1 afirma que "[...] últimos dias estamos apresentando alguns sintomas". Assim cabe ao poder público também garantir a proteção da saúde daqueles que protegem as crianças e adolescentes, garantindo assim, serviços públicos eficientes.

\section{Considerações Finais}

Embora os riscos de contágio dos conselheiros tutelares, eles buscam garantir em tempos de pandemia que os direitos das crianças e adolescentes não sejam violados, embora vivenciarem alguns desafios territoriais.

As ações de prevenção identificadas nesta pesquisa foram: a) ações realizadas junto ao comitê local no início da pandemia b) orientação por meio das redes sociais e WhatsApp e; c) visitas in loco quando solicitado ou identificado a necessidade pelo comitê local. Contudo, na zona rural (comunidades indígenas e ribeirinhas) algumas dessas ações podem ser prejudicadas por falta de infraestrutura logística e tecnológica.

Os direitos violados identificados em períodos de pandemia foram a negligência, maus tratos e o trabalho infantil no comercio informal. Acredita-se também que possa existir o trabalho infantil doméstico e no campo neste contexto de pandemia.

Neste sentido, algumas ações podem ser tomadas como: a) o mapeamento dos bairros onde ocorrem esses tipos de violação; b) orientação as famílias quanto a esse tipo de violação; c) capacitar e orientar as lideranças das comunidades rurais, para criar um comitê comunitário para garantir o direito das crianças e adolescentes em período de pandemia e; d) Maior apoio do governo local para as ações do conselho.

\section{Referências bibliográficas}

Atlas dos Objetivos de Desenvolvimento Sustentável no Amazonas (2020). Universidade Federal do Amazonas (UFAM), Programa de Programa de Pós-Graduação em Ciências do Ambiente e Sustentabilidade na Amazônia (PPGCASA). Manaus: UFAM/ PPGCASA (en línea). http://bit.ly/odsamazonas/, acesso 14 de maio de 2020.

Bahia, C. J. A. B., de Toledo, C. M. Q. (2020). O estado e seu dever inafastável de concretização do direito fundamental à convivência familiar e comunitária de crianças e adolescentes também em tempos extraordinários: a COVID 19 e a concessão do auxílio emergencial retratado pela lei n. ${ }^{\circ}$ 13.982/2020. Relações Internacionais no Mundo Atual, 1(26), 208-222 (en línea). http://dx.doi.org/10.21902/Revrima.v1i26.4060

Bardin, L. (2006). Análise de conteúdo. 2. tiragem. Lisboa/Portugal: Edições, 70.

Decreto $n^{\circ}$ 077, de 19 de março de 2020. (2020). Cria o comitê municipal de prevenção e enfrentamento ao contágio pelo novo coronavírus - covid-19, nomeia os membros do comitê e, dá outras providências. Diário Oficial dos Municípios do Estado do Amazonas. Benjamin Constant, AM: Gabinete do Prefeito. 
Decreto No 080, 23 De Março De 2020 (2020). Declara a emergência no município de Benjamin Constant/AM, enquanto perdurar a emergência em saúde pública de importância nacional em decorrência do novo coronavirus (COVID-19), e dá outras providências. Diário Oficial dos Municípios do Estado do Amazonas. Benjamin Constant, AM: Gabinete do Prefeito.

Decreto $\mathrm{N}^{\mathrm{o}}$ 102, 01 de Maio de 2020. Prorroga os prazos das restrições dos decretos municipais e dá outras providências. Diário Oficial dos Municípios do Estado do Amazonas. Benjamin Constant, AM: Gabinete do Prefeito.

Lei n.8069, de 13 de junho de 1990. (1990). Dispõe sobre o Estatuto da Criança e do Adolescente e dá outras providências. Diário Oficial da União. Brasília, DF: Presidencia da república.

Marques, E. S., Moraes, C. L. D., Hasselmann, M. H., Deslandes, S. F., Reichenheim, M. E. (2020). A violência contra mulheres, crianças e adolescentes em tempos de pandemia pela COVID-19: panorama, motivações e formas de enfrentamento. Cadernos de Saúde Pública, 36, e00074420. Doi: https://doi.org/10.1590/0102-311X00074420

Pineda, C. N., Olavo, A. V. A., Andrade, H. C. P. (2019). Los niños y los jóvenes en dos ciudades de la frontera amazónica: Benjamin Constant (Brasil) e Islandia (Perú). De los derechos de ciudadanía a la violência infantil-juvenil. In C. V. Alcaíde, B. S. Crovetto (org), VIII Congreso Mundial por los direchos de la infancia y la adolescencia. Wolters Kluwer España, S.A: Madrid.

Romagnoli, R. C., Silva, B. C. (2019). A inserção do Conselho Tutelar na prática da intersetorialidade. Gerais: Revista Interinstitucional de Psicologia, 12(2), 210-224. http://dx.doi.org/10.36298/gerais2019120203

Van Lancker, W., Parolin, Z. (2020). COVID-19, school closures, and child poverty: a social crisis in the making. The Lancet Public Health, 5(5), e243-e244. https://doi.org/10.1016/S2468-2667(20)30084-0 